\title{
Acid induced arsenic removal from soil amended with clay-biochar composite
}

\author{
M. Vithanage ${ }^{1}$, L. Weerasundara ${ }^{2}$ \& A.K. Ghosh ${ }^{3}$ \\ ${ }^{1}$ Ecosphere Resilience Research Center, Faculty of Applied Science, \\ University of Sri Jayewardenepura, Nugegoda, Sri Lanka \\ ${ }^{2}$ Environmental Chemodynamics Project, National Institute of Fundamental Studies, Kandy, Sri Lanka \\ ${ }^{3}$ Environmental Mahavir Cancer Institute and Research Centre, Patna, India
}

\begin{abstract}
Phytoremediation itself is not efficient enough to remove As from soil as all As bound fractions are not available for plants. Therefore, the use of extracting agent has been common. However, in general high potential for extraction have been seen by extracting agents like EDTA which is recognized as somewhat toxic. Not many studies showed the potential of organic acids with composites enhancing the extracting capacity. Therefore, three organic acids; acetic, citric and oxalic, and three inorganic acids; sulfuric, nitric, hydrochloric, were used to evaluate the desorption capacity of As into the soil solution from As contaminated soil together with two types of modified BC composites; Biochar-montmorillonite (BC-MT) and Biochar-Natural Red-Earth (BC$\mathrm{RE}$ ). Citric acid showed the better performance with As release compared to all other organic and inorganic acids which is $60 \%$ of the aqua regia digested arsenic in soil at highest acid concentration of $10 \mathrm{mM}$. The use of BC composites further enhanced the capability of As desorption with citric acid. The biochar-montmorillonite (BCMT) composite showed $90 \%$ of desorption capacity with citric acid and for biochar-red earth (BC-RE) composite it was a $95 \%$ of escalation. Therefore, the citric acid with the presence of BC-MT and BC-RE composites have higher capacity to enhance the As desorption from As contaminated soils.
\end{abstract}

\section{INTRODUCTION}

Phytoextraction has many limitations, since minute concentrations are taken up by plants whereas chemically induced phytoextraction has been proposed as an alternative to clean up metal-contaminated soils (Alkorta et al., 2004). Various types of chelating agent, including ethylene diamine tetraaceticacid (EDTA) is used as efficient synthetic chelating agent for increasing the concentration of various metals in the aboveground biomass of plants however, EDTA leaching results surface and groundwater pollution (Evangelou et al., 2007). In comparison with EDTA, low molecular weight (LMW)-organic and inorganic acids, are alternatives to assist with metal phytoextraction. At the same time, Biochar (BC) is a soil amendment which is mostly used to immobilize the heavy metals and metalloids in soil (Kumarathilaka et al., 2018). Hence, three organic and inorganic acids were assessed in order to evaluate the possibility of cleaning As contaminated soil through enhancing its mobility and two $\mathrm{BC}$ composites; biochar-montmorillonite (BC-MT) and biochar-red earth (BC-RE) were used to assess the capability to trigger the clean-up process in As contaminated soils.

\section{METHODS}

Arsenic contaminated soil was obtained from As contaminated site in Naya Tola, Maner, India, was used.
The soil was air-dried and mechanically sieved to $<1 \mathrm{~mm}$ fraction. The $\mathrm{pH}$ and electrical conductivity (EC) of the soil were measured in 1:10 suspension of soil-to-water whereas the total As concentration in soil was measured with aqua regia. Cation exchange capacity (CEC), Total organic carbon (TOC), available phosphate $\left(\mathrm{PO}_{4}^{3-}\right)$ and nitrate $\left(\mathrm{NO}_{3}^{-}\right)$. As per the methods in Vithanage et al., (2014).

\subsection{Preparation of biochar composites}

Montmorillonite (MT) and red earth (RE) clay were dissolved in distilled water to prepare $25 \mathrm{~g} \mathrm{~L}^{-1}$ clay suspensions separately. $250 \mathrm{~g}$ of $\mathrm{BC}$ was added into $2 \mathrm{~L}$ of solution and then the mixtures were shaken for two hours in a mechanical shaker and oven dried. Then the slow pyrolysis process was used at the rate of $7^{\circ} \mathrm{C} \mathrm{min}^{-1}$ under limited oxygen condition at $500^{\circ} \mathrm{C}$ and held constant for $30 \mathrm{~min}$.

\subsection{Acid experiments}

Three organic (acetic, citric and oxalic) and three inorganic (sulfuric, nitric and hydrochloric) acids of different concentrations $(0.05,0.1,0.5,1.0,5.0$ and $10 \mathrm{mM}$ ) were used to evaluate the As release in the As contaminated soil. Approximately, $1 \mathrm{~mL}$ of chloroform was added per liter of all organic acid solutions in order to prevent microbial breakdown of the organic acids. As contaminated soil $\left(20 \mathrm{~g} \mathrm{~L}^{-1}\right)$ was placed in polyethylene tubes and $40 \mathrm{~mL}$ of each acid was added with different concentrations to assess the As release 
Table 1. Physico-chemical properties of As contaminated soil and biochar composites.

\begin{tabular}{|c|c|c|c|c|c|}
\hline Soil & & $\begin{array}{l}\text { BC-MT } \\
\text { composite }\end{array}$ & & $\begin{array}{l}\text { BC-RE } \\
\text { composite }\end{array}$ & \\
\hline $\mathrm{pH}$ & 7.47 & $\mathrm{pH}$ & 9.51 & $\mathrm{pH}$ & 8.99 \\
\hline $\mathrm{EC}\left(\mu \mathrm{S} \mathrm{cm}^{-1}\right)$ & 7.21 & & & & \\
\hline Total As $\left(\mathrm{mg} \mathrm{kg}^{-1}\right)$ & 4.61 & & & & \\
\hline $\begin{array}{l}\text { Available } \mathrm{NO}_{3}^{-} \\
\left(\mathrm{mg} \mathrm{kg}^{-1}\right)\end{array}$ & 2.19 & $\begin{array}{l}\mathrm{EC} \\
\left(\mu \mathrm{S} \mathrm{cm}^{-1}\right)\end{array}$ & 1799 & $\begin{array}{l}\mathrm{EC} \\
\left(\mu \mathrm{S} \mathrm{cm}^{-1}\right)\end{array}$ & 1049 \\
\hline $\begin{array}{l}\text { Available } \mathrm{PO}_{4}^{-3} \\
\left(\mathrm{mg} \mathrm{kg}^{-1}\right)\end{array}$ & 2.79 & & & & \\
\hline TOC $\%$ & 2.59 & & & & \\
\hline $\mathrm{CEC}\left(\mathrm{cmol} \mathrm{kg}^{-1}\right)$ & 7.16 & & & & \\
\hline
\end{tabular}

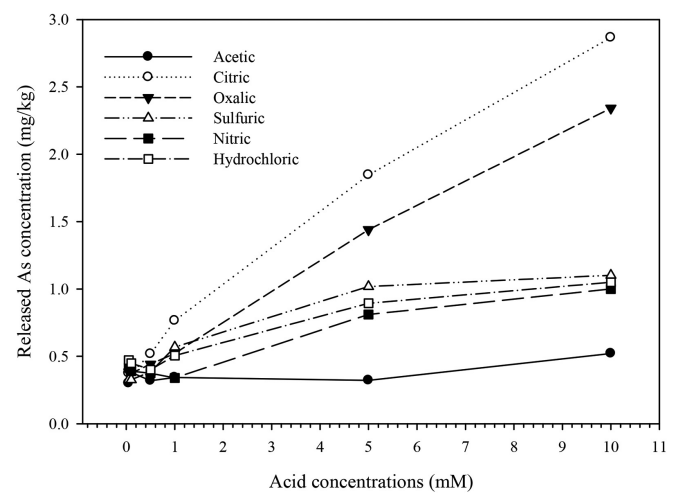

Figure 1. As release with organic and inorganic acids.

rate in bare soil. To assess the influence of $\mathrm{BC}$ composites $2.5 \mathrm{wt} \% \mathrm{BC}$ were added to the same weight of soil and $20 \mathrm{~mL}$ of each acid was added separately. These tubes were equilibrated for $24 \mathrm{~h}$ at room temperature $\left(\sim 26^{\circ} \mathrm{C}\right)$ and agitated on a mechanical shaker at $100 \mathrm{rpm}$. The supernatant was filtered after centrifugation. The filtered solutions were analyzed for $\mathrm{pH}$ and As concentrations were measured with ICP-OES.

\section{RESULTS AND DISCUSSION}

The soil and BC characterization data are depicted in Table 1 . The total and DTPA extractable metal concentration are almost same for As contaminated soil and therefore it can be suggested that all the As in soil is in its bioavailable form.

The As release rates with different organic acids and inorganic acids and inorganic acids are presented in Figure 1.

The inorganic acids showed the weakest As desorption rates compared to organic acids except acetic acid. However, acetic acid is at the lowest place in the means of As release. Citric acid shows the most effective with As desorption. Addition of citric acid could decrease the soil $\mathrm{pH}$ by approximately 3 units at the highest concentration (10 mM). Therefore, use of higher concentrations of citric acid may not efficient

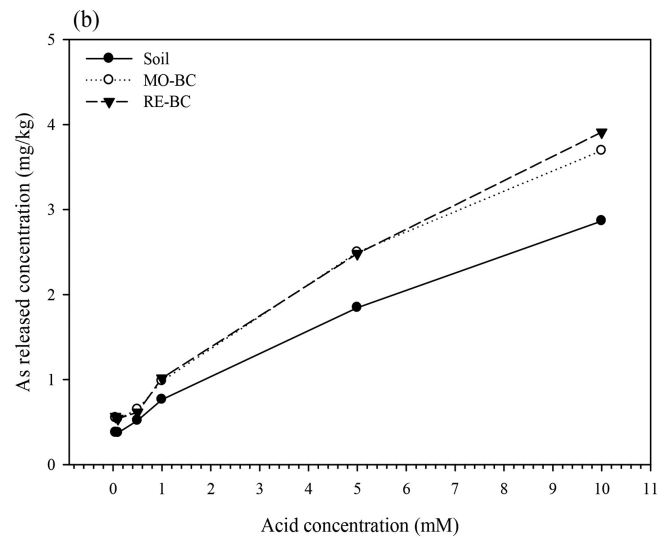

Figure 2. Arsenic release with citric acid with the presence of biochar composites.

for the As desorption in the means of effects on soil quality and plant growth.

Figure 2 shows the way in which different inorganic and organic acids are responded to the BC-MT and $\mathrm{BC}-\mathrm{RE}$ in the means of As desorption. Citric acid could release almost all the bio-available As fraction into the soil solution with the percentage of $95 \%$ with BC-RE composite. However, the two $\mathrm{BC}$ composite types did not show significant different as the $\mathrm{BC}-\mathrm{MO}$ showed $90 \%$ release of As into the soil solution.

\section{CONCLUSIONS}

Citric acid showed the highest performance for As desorption than any other organic and/or inorganic acid type with approximately $70 \%$ of desorption capacity. Both $\mathrm{BC}$ types were showed significant triggering capability for As desorption with citric acids as $90 \%$ for BC-MT and $95 \%$ for BC-RE. Therefore, the use of BC-MT and BC-RE with citric acid pose significant potential to desorption of As from As contaminated soils.

\section{REFERENCES}

Alkorta, I., Hernández-Allica, J., Becerril, J.M., Amezaga, I., Albizu, I., Onaindia, M. \& Garbisu, C. 2004. Chelateenhanced phytoremediation of soils polluted with heavy metals. Rev. Environ. Sci. Bio. 3(1): 55-70.

Evangelou, M.W.H., Ebel, M. \& Schaeffer, A. 2007. Chelate assisted phytoextraction of heavy metals from soil. Effect, mechanism, toxicity, and fate of chelating agents. Chemosphere 68(6): 989-1003.

Kumarathilaka, P., Ahmad, M., Herath, I., Mahatantila, K., Athapattu, B., Rinklebe, J., Ok, Y.S., Usman, A., Al-Wabel, M.I. \& Abduljabbar, A.. 2018. Influence of bioenergy waste biochar on proton-and ligand-promoted release of $\mathrm{Pb}$ and $\mathrm{Cu}$ in a shooting range soil. Sci. Total Environ. 625: 547-554.

Vithanage, M., Rajapaksha, A.U., Oze, C., Rajakaruna, N. \& Dissanayake, C. 2014. Metal release from serpentine soils in Sri Lanka. Environ. Monit. Assess. 186(6): 3415-3429. 